\title{
Usefulness of Ultrasonography to Predict Response to Injection Therapy in Carpal Tunnel Syndrome
}

\author{
Jin Seok Jeong, M.D., Joon Shik Yoon, M.D., Sei Joo Kim, M.D., Byung Kyu Park, M.D., \\ Sun Jae Won, M.D., Jung Mo Cho, M.D., Chan Woo Byun, M.D.
}

Department of Physical Medicine and Rehabilitation, Korea University College of Medicine, Seoul 152-703, Korea

Objective To verify the feasibility of initial parameters of ultrasonography or electromyography for the prediction of effect after steroid injection therapy in a carpal tunnel syndrome (CTS) patient.

Method We recruited individuals with clinical and electrodiagnostic evidence of CTS. Results from the Boston self-assessment questionnaire, median motor and sensory nerve conduction studies, and median nerve ultrasonography were evaluated at baseline, 1 month, and 6 months after injection. Evaluation of median nerve ultrasonography parameters included measurements taken at the maximal swelling point (MS), $2 \mathrm{~cm}$ proximal from MS (2MS), and $12 \mathrm{~cm}$ proximal from MS (12MS), and its ratio (MS/12MS, 2MS/12MS) was calculated. The correlation between improvement of the symptom score after treatment and baseline parameters was estimated. Results Fourteen individuals (14 women, mean age 53.8 years) with 22 affected wrists were enrolled. After steroid injection therapy, clinical and electromyographic parameters showed significant improvements at 1 month or 6 months after injection, and ultrasonographic parameters showed significant changes in maximal area and area ratio (MS/12MS) of the median nerve. Symptom score improvement showed a positive correlation in the initial $2 \mathrm{MS}$ and ratio of $2 \mathrm{MS} / 12 \mathrm{MS}$ after 6 months $(\mathrm{p}<0.05)$.

Conclusion Most of the improvements occurred during the first month after injection and lasted up to 6 months. The initial median nerve swelling and its ratio may be a useful predictor of response after steroid injection.

Key Words Carpal tunnel syndrome, Ultrasonography, Area ratio, Injection, Predictor

Received August 26, 2010; Accepted January 8, 2011

Corresponding author: Joon Shik Yoon

Department of Physical Medicine and Rehabilitation, Korea University College of Medicine Guro Hospital, 97, Guro-dong, Guro-gu, Seoul 152703, Korea

Tel: +82-2-2626-1500, Fax: +82-2-859-5422, E-mail: rehab46@korea.ac.kr Copyright $\odot 2011$ by Korean Academy of Rehabilitation Medicine

\section{INTRODUCTION}

Carpal tunnel syndrome (CTS), which is the most common disorder of peripheral neuropathy, is diagnosed based on medical history, physical examination, and electrodiagnostic (EDX) examination. ${ }^{1,2}$ EDX examination is extremely useful for evaluation of the location of lesions and the severity of entrapment peripheral neuropathy. ${ }^{3}$

Recently, many studies involving ultrasonography have 
been conducted because the method is non-invasive, provides a real-time anatomical image of lesions, and it has been reported to help in the diagnosis of CTS. ${ }^{4}$

There are various CTS treatment options including nonsteroidal anti-inflammatory drugs, wrist splinting, steroid injection, and surgery. Among these methods, steroid injection is frequently used as an easy, simple, safe, and effective treatment. ${ }^{5}$

However, the long-term effects of steroid injections for CTS are debatable, and EDX parameters have shown limited improvement, when compared to clinical improvements. ${ }^{6-8}$

There have also been several studies conducted to investigate ultrasonographic changes following CTS surgery. However, few studies have been conducted to investigate ultrasonographic changes after steroid injection. Indeed, no studies have been conducted for follow-up of EDX examination with ultrasonography.

Therefore, in this study, we evaluated the longterm effects of steroid injection in CTS patients by using changes in clinical, EDX, and ultrasonographic parameters. In addition, we examined the feasibility of using initial parameters to predict the effects of steroid injection therapy in CTS patients.

\section{MATERIALS AND METHODS}

\section{Subjects}

CTS patients were enrolled based on their EDX criteria and clinical symptoms such as tingling sensation or pain in the first to third fingers, burning sensation, paresthesia, weakness of hand grip power, and muscle atrophy.

Patients with underlying metabolic disorders such as diabetes mellitus, genetic disorders, upper limb surgery, peripheral polyneuropathy, and traumatic nerve injury were excluded from this study.

\section{Methods}

Clinical assessment was conducted using the Boston self-assessment questionnaire (BQ), which is the most commonly used outcome measure of assessment for improvements in clinical symptoms and functional recovery of patients with CTS.

EDX examination was conducted using Nicolet Viking IV $^{\circledR}$ (Nicolet Biomedical, Madison, WI, USA). Skin temperature of the hand was maintained above $32^{\circ} \mathrm{C}$, while a median motor nerve conduction study was employed to record the initial latency and baseline to peak amplitude from the abductor pollicis brevis muscle center (active site) while stimulation was performed at the wrist, $7 \mathrm{~cm}$ from the recording site. A median sensory nerve conduction study was employed to record the initial latency and baseline to peak amplitude from the $3^{\text {rd }}$ finger (active site), with retrograde stimulation being conducted at the wrist $(14 \mathrm{~cm}$ proximal area from the recording site) and the palm ( $7 \mathrm{~cm}$ proximal area from the recording site). The EDX criteria of CTS was determined based on a median motor latency $>4.2 \mathrm{~ms}$, median sensory onset latency $>3.8 \mathrm{~ms}$, or a ratio of proximal and distal onset latency $>2.0 .^{9}$

Ultrasonography studies were performed using a HDI 3500 (ATL ${ }^{\circledR}$, Bothell, WA, USA) with a $12 \mathrm{MHz}$ line array transducer. A physician, blinded to the EDX findings and clinical parameters, evaluated ultrasonography results. A perpendicular angle of the probe was maintained during analysis to prevent anisotropy and median nerve deformation, and additional weight was not permitted when pressure was applied on the skin surface with the probe. During analysis, patients were maintained in the supine position, with the forearm supinated and the wrist placed in a neutral position to prevent the appearance of the median nerve from changing according to wrist position. Cross-sectional area (CSA) was measured at 3 locations. The 3 locations of the median nerve ultrasonographic parameters included the maximal swelling point (MS) of the median nerve, $2 \mathrm{~cm}$ proximal from MS (2MS), and $12 \mathrm{~cm}$ proximal from MS (12MS). Following measurement, the CSA was calculated.

The CSA of the median nerve was measured by continuous tracing of the nerve circumference, excluding the hyperechoic epineuria rim. The average value was reported based on 3 measurements. Using the CSAs of MS, 2MS, and 12MS, the CSA ratio of the median nerve was then calculated (MS/12MS, 2MS/12MS) (Fig. 1). ${ }^{9}$

Each assessment was conducted at baseline, 1 month, and 6 months after injection.

Conversely, to predict the effect after a steroid injection, the correlation between improvement of the symptom score after 1 and 6 months of treatment, and baseline EDX and ultrasonographic parameters was estimated. 

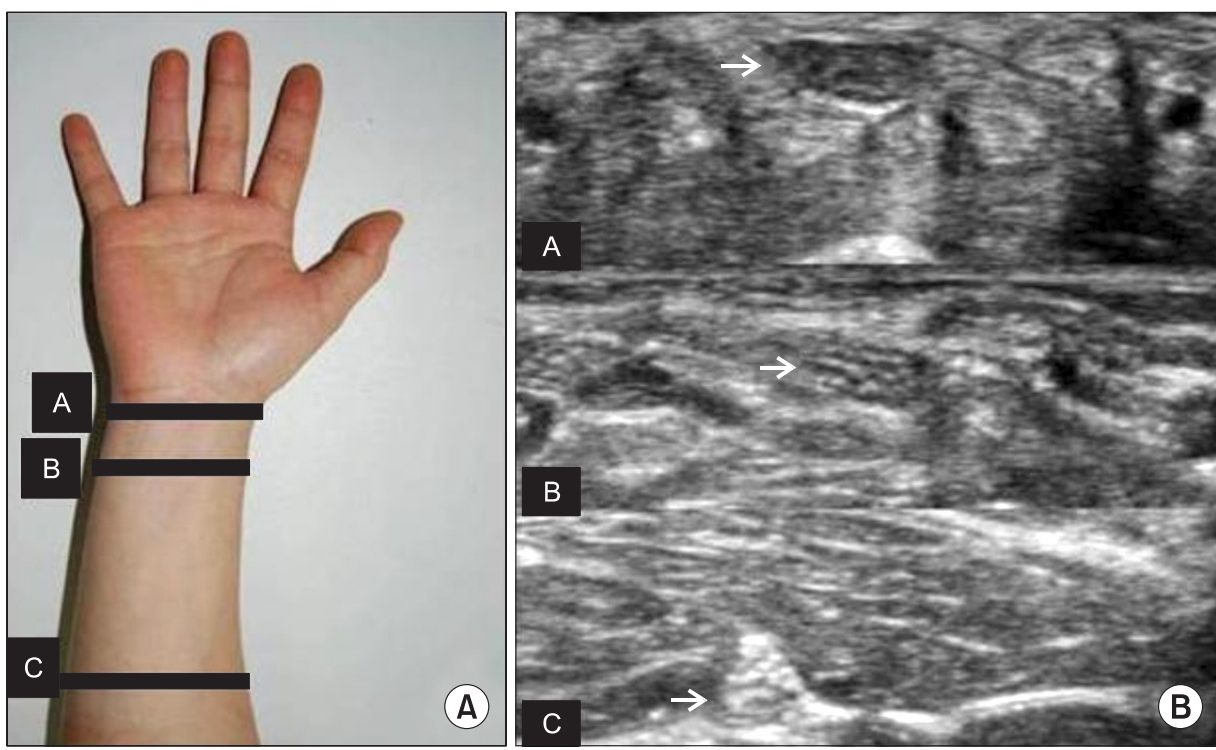

Fig. 1. (A) Placement of ultrasonographic probe at the forearm. Ultrasonographic transverse scan was done at 3 different levels. We measured the cross sectional area of median nerve at the most swollen site level A, $2 \mathrm{~cm}$ proximal to this level $\mathrm{B}, 12 \mathrm{~cm}$ proximal to this level C. We calculated ratio of A/C, B/C. (B) Median nerve transverse sonogram image at A, B, C level.
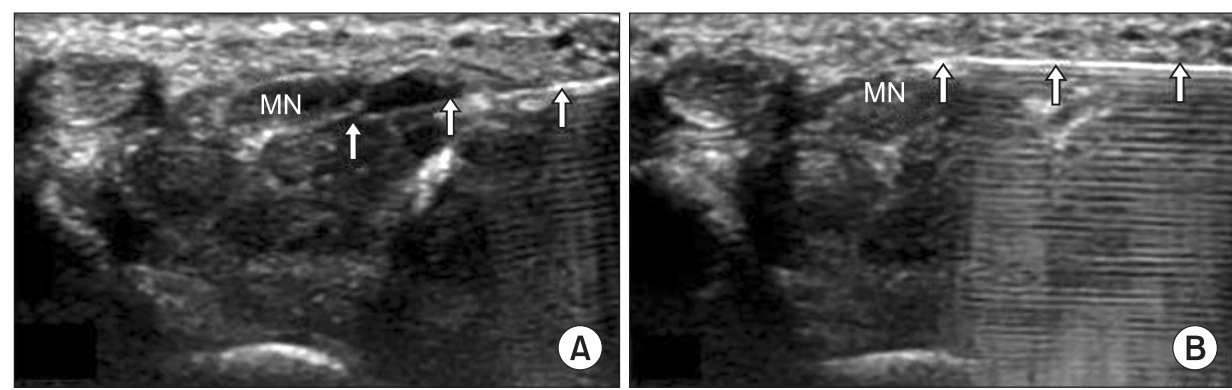

Fig. 2. Transverse sonogram of the carpal tunnel in a patient with idiopathic carpal tunnel syndrome. (A) A 26-gauge needle (arrow) is shown passing from the ulnar aspect of the carpal tunnel to a position adjacent and deep to the median nerve. (B) A 26-gauge needle (arrow) is shown passing from the ulnar aspect of the carpal tunnel to a position adjacent to the median nerve just below flexor retinaculum. MN: Median nerve .

\section{Injection technique}

The injection technique was conducted using the ulnar side approach proposed by Smith et al. ${ }^{10}$ Briefly, with the wrist placed in a slight dorsiflexion, the injection was conducted under sterile conditions using a 26 -gauge needle. Using real-time ultrasonography, $20 \mathrm{mg}$ triamcinolone was injected into the ulnar side.

Specifically, $10 \mathrm{mg}$ of triamcinolone was injected over the median nerve and under the flexor retinaculum, while the remainder was injected under the median nerve (Fig. 2). If the patient complained of paresthesia at the injection site, the needle was immediately withdrawn and repositioned.

\section{Statistical analysis}

Statistical analysis was conducted using SPSS 12.0. All parameters were calculated based on the mean and standard deviation, and were verified by the KolmogorovSmirnov test. Repeated measures ANOVA was used to compare before and after injection parameters. The Spearman rank test was employed to identify the correlation of the degree of clinical improvement and initial parameters in the injection. p-values less than 0.05 was considered to indicate statistical significance.

\section{RESULTS}

Fourteen individuals (all women, mean age 53.8 years) with 22 affected wrists were enrolled in this study (Table 1). Most parameters showed significant improvement at 1 month or 6 months after injection when they were compared with baseline parameters (Table 2). 
Table 1. General Characteristics of Subjects

\begin{tabular}{|lc}
\hline \multicolumn{1}{c}{ Characteristic } & Data \\
\hline Sex M : F & $0: 14$ \\
\hline Age (year) & $53.8 \pm 11.1$ \\
\hline Symptom duration (months) & $6.2 \pm 6.7$ \\
\hline Two hands affected & 8 \\
\hline Only right hand affected & 3 \\
\hline Only left hand affected & 3 \\
\hline Initial Pauda* scale & $3.9 \pm 0.3$ \\
\hline Initial HiOb scale & $3 \pm 0.7$ \\
\hline
\end{tabular}

Values are mean \pm standard deviation

HiOb: Historical-Objective scale

*Electrophysiological Padua proposal scale

Additionally, when compared with baseline parameters (mean 25.6), clinical parameters showed significant improvement at 1 month (mean 15.8) and 6 months (mean 14.7) after steroid injection.

Motor nerve latency and amplitude showed reduced and increased patterns with time, but latency differed significantly at 6 months after steroid injection $(\mathrm{p}<0.05)$. Sensory nerve latency and amplitude also showed shortened and increased patterns, but the latency differed significantly at 1 month and the amplitude differed significantly at 6 months after steroid injection $(\mathrm{p}<0.05)$.

When compared with baseline parameters (mean 15.7 $\mathrm{mm}^{2}$ ), median nerve maximal swelling CSA showed significant improvement at 1 month (mean $12.8 \mathrm{~mm}^{2}$ ) and 6 months (mean $12.3 \mathrm{~mm}^{2}$ ) after steroid injection.

The CSA ratio of the maximum swelling point (MS/12MS) also differed significantly following steroid injection $(\mathrm{p}<0.05)$. The CSA of $2 \mathrm{MS}$ and its ratio (2MS/12MS) showed a decreasing pattern following injection, but these findings did not differ significantly.

When the results obtained at 1 and 6 months were compared, motor latency and sensory amplitude showed significant improvements, but the other parameters did not differ significantly.

To verify the feasibility of the initial parameters for the prediction of effect after steroid injection therapy in CTS patients, we examined the Spearman rank test to identify the correlation of the degree of clinical improvement with the initial parameters (Table 3).

EDX examination did not include prediction parameters, but the improvement in clinical score was
Table 2. Clinical, Electromyographic, and Ultrasonographic Data at Baseline, 1 and 6 Months after Injection $(\mathrm{n}=22)$

\begin{tabular}{|c|c|c|c|}
\hline & Baseline & 1 month & 6 months \\
\hline Symptom score & $25.6 \pm 7.4$ & $15.8 \pm 6.0^{*}$ & $14.7 \pm 4.4^{*}$ \\
\hline Functional score & $13.2 \pm 4.6$ & $10.2 \pm 3.2^{*}$ & $10.4 \pm 3.5^{*}$ \\
\hline Motor latency (ms) & $5.3 \pm 1.2$ & $5.1 \pm 1.1$ & $4.6 \pm 0.6^{*}$ \\
\hline Motor amplitude (mV) & $6.5 \pm 2.3$ & $7.5 \pm 3.0^{*}$ & $7.7 \pm 2.4^{*}$ \\
\hline Sensory latency (ms) & $4.5 \pm 1.3$ & $4.2 \pm 1.2^{*}$ & $4.2 \pm 0.6$ \\
\hline Sensory amplitude (uV) & $16.9 \pm 10.2$ & $18.3 \pm 8.5$ & $22.5 \pm 13.1^{*}$ \\
\hline CSA at the wrist $\left(\mathrm{mm}^{2}\right)$ & $15.7 \pm 3.7$ & $12.8 \pm 4.0^{*}$ & $12.3 \pm 3.9^{*}$ \\
\hline $\begin{array}{l}\text { CSA at } 2 \mathrm{~cm} \text { proximal } \\
\text { of maximal CSA area } \\
\left(\mathrm{mm}^{2}\right)\end{array}$ & $10.6 \pm 2.6$ & $9.8 \pm 2.8$ & $9.9 \pm 3.1$ \\
\hline $\begin{array}{l}\text { Median nerve area ratio } \\
\left({\text { maximal })^{\dagger}}^{\dagger}\right.\end{array}$ & $2.7 \pm 0.9$ & $2.2 \pm 0.8^{*}$ & $2.1 \pm 0.7^{*}$ \\
\hline $\begin{array}{l}\text { Median nerve area ratio } \\
(2 \mathrm{~cm} \text { proximal })^{\dagger}\end{array}$ & $1.8 \pm 0.5$ & $1.8 \pm 0.6$ & $1.7 \pm 0.6$ \\
\hline
\end{tabular}

Values are mean \pm standard deviation

CSA: Cross sectional area

*The results of comparison between baseline, 1 month, and 6 months using repeated measure ANOVA are statistically significant at $\mathrm{p}<0.05,{ }^{\dagger}$ Ratio of most swelling site to $12 \mathrm{~cm}$ proximal, ${ }^{*}$ Ratio of $2 \mathrm{~cm}$ proximal site to 12 $\mathrm{cm}$ proximal

positively related to the initial $2 \mathrm{MS}$ (mean $10.6 \mathrm{~mm}^{2}, \mathrm{r}=$ $0.510, \mathrm{p}=0.022$ ) and $2 \mathrm{MS} / 12 \mathrm{MS}$ ratio (mean $1.8, \mathrm{r}=0.529$, $\mathrm{p}=0.017$ ).

\section{DISCUSSION}

Steroid injection is known to be a safe and effective treatment in CTS patients, and relieves local ischemia, inflammation, synovial swelling around the median nerve, and vascular congestion in carpal tunnel. ${ }^{11,12}$

Clinical and EDX parameters have been used to evaluate the effectiveness of injection therapy. However, although EDX and clinical parameters showed significant improvement following steroid injection, there is no known correlation between EDX values and clinical scales. ${ }^{13}$ In addition, the EDX test cannot be used to investigate anatomical variance because it is invasive, costly, and time consuming. Therefore, it is unreasonable to use EDX for long term follow-up of the effects of steroids.

Conversely, high-resolution ultrasonography enables 
Table 3. Spearman Correlation Coefficients of Symptom Improving and Baseline Parameters $(\mathrm{n}=22)$

\begin{tabular}{lcc}
\hline & $\begin{array}{c}\text { Correlation } \\
\text { coefficient }\end{array}$ & p-value \\
\hline Motor latency $(\mathrm{ms})$ & 0.351 & 0.129 \\
\hline Motor amplitude $(\mathrm{mV})$ & -0.414 & 0.070 \\
\hline Sensory latency $(\mathrm{ms})$ & -0.035 & 0.884 \\
\hline Sensory amplitude $(\mathrm{uV})$ & 0.000 & 1.000 \\
\hline $\begin{array}{l}\text { CSA at the wrist, maximal } \\
\left(\mathrm{mm}^{2}\right)\end{array}$ & 0.386 & 0.092 \\
$\begin{array}{l}\mathrm{CSA} \text { at } 2 \mathrm{~cm} \text { proximal of } \\
\text { maximal CSA area }\end{array}$ & 0.510 & $0.022^{*}$ \\
$\begin{array}{l}\text { Median nerve area ratio } \\
(\text { maximal) }\end{array}$ & 0.303 & 0.194 \\
\hline $\begin{array}{l}\text { Median nerve area ratio } \\
(2 \mathrm{~cm} \text { proximal) }\end{array}$ & 0.529 & $0.017^{*}$ \\
\hline
\end{tabular}

CSA: Cross sectional area

${ }^{*} \mathrm{p}<0.05$, ${ }^{\dagger}$ Ratio of most swelling site to $12 \mathrm{~cm}$ proximal,

${ }^{*}$ Ratio of $2 \mathrm{~cm}$ proximal site to $12 \mathrm{~cm}$ proximal

evaluation of the peripheral nerve anatomy without irradiation; blood flow can be viewed through Doppler imaging and it is non-invasive, less expensive, and less time consuming than EDX.

Mondelli et al. ${ }^{14}$ reported post-operative changes in CTS patients. They found that ultrasonography was useful for the diagnosis of CTS, providing anatomical images of the median nerve, carpal tunnel, and neighboring structures, as well as for demonstrating improvement following surgical release. Moreover, they found direct correlations between CSA of the median nerve inlet and the clinical scale. In other words, the presurgical median nerve size of carpal tunnel inlet was smaller, the symptom scale easily decreased to the threshold level, so better outcomes are predicted. However, in this study, no correlation was observed between the $\mathrm{BQ}$ score and the CSA of the median nerve.

Conversely, Naranjo et al. ${ }^{15}$ conducted similar studies of postsurgery CTS patients. No correlation was found between the maximum CSA of the presurgical median nerve size and clinical scale improvement. Thus, the median nerve CSA measured by ultrasonography was useful for prediction of effect in CTS patients. Although these studies were conducted with postsurgical CTS patients, our study showed similar results.

Cho et al. ${ }^{9}$ reported that maximal CSA and its ratio can be used to reduce false positive findings due to median nerve CSA variations and interobserver differences.

In this study, we identified the effects of CTS injection therapy with EDX and ultrasonography and found that they were similar to the results of a previous study. Specifically, the median nerve CSA and its ratio measured by ultrasonography showed significant improvement after steroid injection. Most improvements occurred during the first month of post-injection and lasted for 6 months after CTS steroid injection therapy.

Baseline 2MS and its ratio measured by ultrasonography may be a useful predictor for the effects of steroid injection, because these parameters were found to be correlated with improvement of the clinical score.

Entrapment peripheral neuropathy showed increasing nerve CSA at the entrapment site, with maximal nerve swelling typically being observed at the flexor retinaculum in CTS.

However, the carpal tunnel is a very narrow space and the flexor retinaculum is a very rigid structure; therefore, nerve swelling is limited to a transverse increase, which results in longitudinal increases. Accordingly, 2MS and its ratio were useful for evaluating the effects of steroid treatment.

Ultrasonography in CTS is variable and controversial, and some studies have evaluated the median nerve CSA at the carpal tunnel inlet, outlet, and mid- portion. ${ }^{14,16,17,19}$ The present study only used the maximal CSA. ${ }^{15}$ After surgery, the CSA-inlet of the median nerve was decreased; however, some studies have shown that the CSA-outlet of the median nerve was increased. ${ }^{14,16,17,19}$

Accordingly, further research is needed to elucidate the mechanism by which median nerve swelling occurs, as well as the mechanism of improvement after treatment.

It is also important to note that the present study was limited, in that only 22 affected wrists were evaluated.

To more clearly investigate the usefulness of ultrasonography to predict the response to injection therapy in CTS, additional studies are needed.

Finally, most of the CTS patients included in this study had mild symptoms; therefore, additional studies are needed to investigate the effects according to the severity of disease.

\section{CONCLUSION}

Most improvements in carpal tunnel symptoms occurred during the first month of post-injection, and effects lasted 
for up to 6 months during CTS steroid injection therapy. The results of this study were confirmed by clinical, EDX, and ultrasonographic tests, and ultrasonography was found to have potential for use as a predictor to select patients after steroid injection, as well as a method for evaluation of steroid injection.

\section{ACKNOWLEDGEMENTS}

This study was supported by a grant from the Korea Healthcare Technology R\&D Project; Ministry for Health, Welfare \& Family Affairs, Republic of Korea.

\section{REFERENCES}

1. Gelberman RH, Rydevik BL, Pess GM, Szabo RM, Lundborg G. Carpal tunnel syndrome. A scientific basis for clinical care. Orthop Clin North Am 1988; 19: 115-124

2. Lee D, van Holsbeeck MT, Janevski PK, Ganos DL, Ditmars DM, Darian VB. Diagnosis of carpal tunnel syndrome. Ultrasound versus electromyography. Radiol Clin North Am 1999; 37: 859-872

3. Jablecki CK, Andary MT, Floeter MK, Miller RG, Quartly CA, Vennix MJ, Wilson JR. Practice parameter: Electrodiagnostic studies in carpal tunnel syndrome. Report of the American Association of Electrodiagnostic Medicine, American Academy of Neurology, and the American Academy of Physical Medicine and Rehabilitation. Neurology 2002; 58: 1589-1592

4. Wong SM, Griffith JF, Hui AC, Lo SK, Fu M, Wong KS. Carpal tunnel syndrome: diagnostic usefulness of sonography. Radiology 2004; 232: 93-99

5. Racasan O, Dubert T. The safest location for steroid injection in the treatment of carpal tunnel syndrome. J Hand Surg Br 2005; 30: 412-414

6. Lee JH, An JH, Lee SH, Hwang EY. Effectiveness of steroid injection in treating patients with moderate and severe degree of carpal tunnel syndrome measured by clinical and electrodiagnostic assessment. Clin J Pain 2009; 25: 111-115

7. Milo R, Kalichman L, Volchek L, Reitblat T. Local corticosteroid treatment for carpal tunnel syndrome: a 6-month clinical and electrophysiological follow-up study. J Back Musculoskelet Rehabil 2009; 22: 59-64
8. Ucan H, Yagci I, Yilmaz L, Yagmurlu F, Keskin D, Bodur H. Comparison of splinting, splinting plus local steroid injection and open carpal tunnel release outcomes in idiopathic carpal tunnel syndrome. Rheumatol Int 2006; 27: 45-51

9. Cho JM, Yoon JS, Kim SJ, Park BK, Lee GH, Jeong JS. Feasibility of ultrasonographic area ratio of median nerve in the diagnosis of carpal tunnel syndrome in Korea. J Korean Acad Rehab Med 2009; 33: 627-631

10. Smith J, Wisniewski SJ, Finnoff JT, Payne JM. Sonographically guided carpal tunnel injections: the ulnar approach. J Ultrasound Med 2008; 27: 1485-1490

11. Armstrong T, Devor W, Borschel L, Contreras R. Intracarpal steroid injection is safe and effective for short-term management of carpal tunnel syndrome. Muscle Nerve 2004; 29: 82-88

12. Hui AC, Wong S, Leung CH, Tong P, Mok V, Poon D, LiTsang CW, Wong LK, Boet R. A randomized controlled trial of surgery vs steroid injection for carpal tunnel syndrome. Neurology 2005; 64: 2074-2078

13. Hagebeuk EE, de Weerd AW. Clinical and electrophysiological follow-up after local steroid injection in the carpal tunnel syndrome. Clin Neurophysiol 2004; 115: 1464-1468

14. Mondelli M, Filippou G, Aretini A, Frediani B, Reale F. Ultrasonography before and after surgery in carpal tunnel syndrome and relationship with clinical and electrophysiological findings. A new outcome predictor? Scand J Rheumatol 2008; 37: 219-224

15. Naranjo A, Ojeda S, Arana V, Baeta P, FernandezPalacios J, Garcia-Duque O, Rodriguez-Lozano C, Carmona L. Usefulness of clinical findings, nerve conduction studies and ultrasonography to predict response to surgical release in idiopathic carpal tunnel syndrome. Clin Exp Rheumatol 2009; 27: 786793

16. Abicalaf CA, de Barros N, Sernik RA, Pimentel BF, Braga-Baiak A, Braga L, Houvet P, Brasseur JL, Roger B, Cerri GG. Ultrasound evaluation of patients with carpal tunnel syndrome before and after endoscopic release of the transverse carpal ligament. Clin Radiol 2007; 62: 891-894

17. Colak A, Kutlay M, Pekkafali Z, Saracoglu M, Demircan N, Simsek H, Akin ON, Kibici K. Use of sonography in carpal tunnel syndrome surgery. A prospective study. Neurol Med Chir 2007; 47: 109-115 
Jin Seok Jeong, et al.

18. Hammer HB, Hovden IA, Haavardsholm EA, Kvien TK. Ultrasonography shows increased cross-sectional area of the median nerve in patients with arthritis and carpal tunnel syndrome. Rheumatology 2006; 45: 584588
19. Lee CH, Kim TK, Yoon ES, Dhong ES. Postoperative morphologic analysis of carpal tunnel syndrome using high-resolution ultrasonography. Ann Plast Surg 2005; 54: $143-146$ 